\title{
The Use of Artificial Intelligence (AI) in Legal Framework for International Arbitration Practices in Indonesia
}

\author{
Flora P. Kalalo ${ }^{1, *}$ Kathleen C. Pontoh ${ }^{1}$ \\ ${ }^{1}$ Faculty of Law Sam Ratulangi University, Manado, North Sulawesi, Indonesia. \\ "Corresponding author. Email: kathleen_pontoh@yahoo.com
}

\begin{abstract}
In the era of The Fourth (4.0) Industrial Revolution, cutting edge technology has made no boundaries between countries in international trade. Nowadays, the engagement between people can easily be done by touching screen. Nevertheless, it has potential to cause legal problems, that is why the resolution of legal disputes also requires the aid of technology. The existence of Artificial Intellegent (AI) and its features greatly facilitates the work of legal practitioners in international arbitration. In making international business agreement documents, legal practitioners is required to have an understanding of international law that is the same as some national legal systems. That is why former advisors and arbitrators spent countless hours for researching and reviewing legal documents. The use of AI not only can shorten the time in making international treaty documents, but also can also provide a broad legal impact to the public, especially business people who resolve their dispute through arbitration. AI is software in a computer system that strongly supports the existence of international trade in making electronic contracts, electronic signatures and other electronic documents in the laws of technology, information and communication. For these reason this paper discusses a juridical analysis on the use of Artificial Intelligence (AI) in legal framework for International Arbitration in Indonesian.
\end{abstract}

\section{Keywords: Artificial Intelligence System, Practice, International Arbitration, Indonesian Legal Framework}

\section{INTRODUCTION}

Nowadays, people live in the era of 4.0 Industrial Revolution or Disruptive era, where advances in technology, along with information and communication have brought many changes in people lifestyle. People in this disruptive era are experiencing very rapid changes in their life patterns, for example, the typical business transactions which is done manually are replaced with online transanction which can be done instantly with the use of internet. Technological sophistication in this era has created law business as if it without limits. According to Soerjono Soekanto, social change is all changes to social institutions that affect their social systems, including values, attitudes and behavior patterns among community groups. In general, a change in a particular field will affect other fields. Therefore, if it is set against the law, will the changes in law extend to alter other fields. [1]

Disruptive Era is an era where something can happen randomly. Both positive and negative things can be viral in just seconds. This is an era where anyone can easily do anything in virtual world. Moreover, anyone should be really careful to do things in virtual world since there are still inequalities between old and new customs that emerged in this era. The phenomenon can affects international business activities, for example in making contracts in electronic form, electronic documents, and electronic signatures. This practice in making everything electronically has a potency to cause disputes among interested parties. The validity of contracts, documents, and electronic signatures in every engagement that arises in international business is a mandatory. In order to ensure authentic contract, documents and electronic signatures, we all need an advance technology to facilitate the settlement of Internasional business disputes. The term of Artificial Intelligence (AI) was proposed by John McCarthy in his research proposal in 1955 which describes the workings of artificial intelligence systems (AI) as a machine that uses language in abstract forms and concepts that can make it easier for humans to solve their problems.[2] According to the BBC, the definition of artificial intelligence system (AI) is a machine that can do various things such as understanding human language naturally, recognizing faces in photos, guessing books that we like, and so on. [3] Some notions of artificial intelligence were brought up by experts, such as H. A. Simon (1987) "artificial intelligence is included in the area of research, application and instruction related to computer programming to do something that in human view is intelligent [4] "Rich and Knight also defined that "Artificial intelligence (AI) is a study of how to make computers do things that humans can now do better. "[4]. Another definition of Artificial intelligence (AI) is the term coined to describe the general process whereby large amounts of data are combined with powerful iterative data processing systems and intelligent algorithms, thereby 
enabling systems the software to learn automatically form patterns or future in the data.

The term AI is often used loosely, and encompasses many subjects including machine learning, deep learning, neural pathways, BOTs, cognitive computing, and natural language processing, but it is the software's ability to learn automatically from patterns or features in the data that makes it 'intelligence'. [5], Since the speech made by Sophie Nappert entitled AI (Artificial Intelligence) and its impact on International Arbitration at the 6th Asia-Pacific Arbitration Disputes Resolution Conference held in Seoul, $\mathrm{AI}$ is one of the hot topics discussed in the international legal domain more specifically in the Asia Pacific Region. This was also the topic of the 25th Conference of the Korea International Lawyers Association. [6] The Pros and Cons of the existence of AI in the realm of International Business Law especially in the settlement of international arbitration disputes is a debate. On one hand AI has a work system that can help discuss, sort and analyze business contracts. Therefore, the understanding of international law needed in the practice of international arbitration and in the legal system of the parties. On the other hand, AI (Artificial Intelligence) is a challenge to the law enforcement stage, requiring skills and human resources capable of technology. In the Law Journal by Phillipe Billet and Filip Nordlund entitled A New beginning - artificial intelligence and arbitration. It was stated that "The potential use for AI (Artificial Intelligence) in Arbitration is endless, but one the most interesting and controversial application would be as an arbitrator, i.e. machine arbitration. Instead of choosing an arbitrator on the basis of nationality, technical know-how and legal expertise, parties would choose a software program. This machine would have the requisite knowledge as specified by the parties and be able to understand an argument, ascertain facts and determine the applicable law while remaining independent and impartial." [6]

The existence of AI (Artificial Intelligence) from the perspectives of its features, greatly facilitates the work of legal practitioners in the practice of international arbitration. In making international business agreement documents, legal practitioners are required to have an understanding of international law that is the same as some national legal systems. That is why former advisors and arbitrators spent countless hours for researching and reviewing legal documents. The use of AI not only can shorten the time in making international treaty documents, but also can also provide a broad legal impact to the public, especially business people who resolve their dispute through arbitration.

In the lives of Indonesians today the use of AI (Artificial Intelligence) has not been used too much and has not yet been explicitly regulated in the Use of AI (Artificial Intelligence) in Indonesian legislation, but this is a future challenge for the existence of Indonesian law in the world International. If later AI (Artificial Intelligence) becomes the necessity of business people and legal practitioners in Indonesia to make understandings of agreements and dispute resolution in the practice of International Arbitration.

\section{Problem Formulation}

Based on the above mentioned reasons, the authors interested in conducting a juridical analysis on the use of AI (Artificial Intelligence) in the practice of International Arbitration within the legal framework in Indonesia.

\section{THEORY AND DISCUSSION}

\subsection{Benefits of AI (Artificial Intelligence) in the practice of International Arbitration.}

The use of Artificial Intelligence (AI) in International Arbitration practices is very useful. For instance, it collected data in video conferencing, it recorded electronically, it scanned document, and it built database. Artificial Intelligence (AI) software is used to analyze the existence of international law in understanding national law to become an international business agreement of the parties. Usually, this work was conducted by legal practitioners. It took extensive time to research and reviewing legal documents, forcing arbitration International practitioners to read many pages of literature and legal documents to study. Artificial Intelligence (AI) is used as an alternative to analyze a number of legal documents that is available online in library database. Thereby, AI help to shorten the period to research and review legal documents. Artificial Intelligence (AI) is a tool to ease the work of legal practitioners in the practice of international arbitration.

Artificial Intelligence (AI) is useful in processing and evaluating tasks in international arbitration. For example, some programs that use predictive coding can produces reviews and finds documents in electronic format, filtering all relevant data to perceive documents. In addition, there are programs that can make predictions, evaluate with a higher degree of accuracy of the likelihood of success or failure of a party to the dispute. [7]

Utilization of Voice Recognition in Artificial Intelligence (AI) technology which is managed to recognize language accents with extraordinary accuracy also identify certain individual voices, such as transcripts with speaker identification, interpretation in communication from parties in different languages and translating documents of other arbitration.

In case of refereeing engagement, Artificial Intelligence (AI) can help by providing a list of prospective arbitrators 
that already exist in the Artificial Intelligence (AI) database by matching potential candidates based on the criteria of arbitrators such as knowledge, experience in certain legal fields.

Considering the benefits of Artificial Intelligence (AI) mentioned above, it is thought that AI would be beneficial for the work of legal practitioners and business people in International Arbitration practices. However, it should also be a concern that Artificial Intelligence (AI) is a new technology that requires improvement and development, so that it demands a collaborative process between software and professional arbitration to identify problems that occur.

\subsection{The impact of storing AI (Artificial Intelligence) database information in the practice of International Arbitration.}

The connection between technological progress with legal issues, government policies, politics, social, and financial matters is a complexity of the problem if it is not handled wisely. On one hand, the storage of AI (Artificial Intelligence) database provides convenience and comfort since it reduces human work. On the other hand, the storage of AI (Artificial Intelligence) data base information can have a negative impact and can endanger the business continuity of the parties.

Some risks of using AI (Artificial Intelligence), such as:

1. Artificial Intelligence (AI) Bias

In March 2016, a chat bot that uses AI (Artificial Intelligence) named Tay, tweeted offensive, racist and pro posts against Adolf Hitler. Tay is a software application made by Microsoft Technology, Research and Bing. The platform services is to interact with internet users around the world. Tay has an account in Twitter and a chat application on GroupMe and KIK. Of these platforms Tay Chatbot powered by AI (Artificial Intelligence) interacts like humans.

2. The possibility of AI (Artificial Intelligence) to be Hacked.

Artificial Intelligence (AI) database information storage allows data to be hacked. Secrecy of trade from the business of the parties can be accessed by parties seeking profits so that confidential data from the company is not safe. Other crimes in cyberspace such as phishing to get user IDs, passwords, other personal data, sending viruses which can disrupt company data to software from other parties who want to make a profit.

\section{AI (Artificial Intelligence) Terorism}

Artificial Intelligence (AI) allows acts of terrorism, autonomous drone expansion and other software applications that might be able to disrupt trade traffic.

\subsection{Use of AI (Artificial Intelligence) in the practice of Arbitration within the legal framework in Indonesia.}

Changes in behavior of people in the Disruptive era are social symptoms that cause social interactions among people to change following the rapid advances in Technology, Information and Communication. According to Van Apeldoorn, the law must be able to explain the social phenomena in the community and it is true that the adage from Cicero that there is a community there is a law (ubi societas ibi ius). In essence, the function of law in society according to Roscoe Pound which adheres to the Sociological Jurisprudence as social control and social engineering.

Optimistic and pessimistic about the use of AI (Artificial Intelligence) will be a dilemma for people in the Disruptive era. For this reason, the law should take over the dilemma in the Disruptive era which functions as social control and social engineering in the community so that inequality does not occur. The law is expected to be able to harmonize the relationship between the use of technological progress and the prevailing norms in society. The link between AI (Artificial Intelligence) and law is an interdisciplinary discussion that directly addresses the understanding and model of the legal framework itself.

The field of law offers many opportunities to develop analytics and the incorporation of the art of computerization of the AI (Artificial Intelligence) Model Legal characteristics. [8] also very unique that makes this field of AI (Artificial Intelligence) very challenging, such as:

1. Legal interpretation into various forms of reasoning that are related to cases, rules, statutory provisions, and legal principles.

2. The legal case also has a style and standard of reasoning and extreme justification.

3. Knowledge of law specifically has references from various sources, including cases, legal rules, documentation, scientific summaries and legal opinions.

4. The law itself can be criticized, has a process of habits and opinions of how much the debate.

5. Legal answers themselves have different characters from other disciplines because they can change over time.

6. Knowledge used for legal reasoning varies, ranging from common sense derived from legal 
knowledge, structural variations in different cases, characters and uses.

Observations allow the synergy between the legal framework and AI (Artificial Intelligence) to have implications for the method of approach to AI (Artificial Intelligence). This approach is based on learning against the background of the cases of AI (Artificial Intelligence) program, we will know models of understanding and concepts of use.

Although Indonesia has Regulations No. 19 of 2016 concerning Electronic Information and Transactions which is an implementation of national law based on the United Nations Commission on International Trade Law Law on Electronic Commerce Model (UNCITRAL Model Law on E-Commerce) and United Nation Commission on International Trade Law Model Law on Electronic Signature (UNCITRAL Model Law on E-Signature), the law has not explicitly regulated the use of AI (Artificial Intelligence).

In general, Regulations Number 19 Year 2016 concerning Information and Economic Transactions has regulated several General Provisions in article 1 paragraph 1 to paragraph 23. But not with definitions and related provisions about AI (Artificial Intelligence) except that in Article 1 paragraph 1 of Regulations Number 19 Year 2016 it mentions the definition of "Electronic Information is one or a collection of electronic data, including but not limited to writing, voice, images, maps, designs, photos, electronic data interchage (EDI), e-mail, telegram, telex, telecopy or the like, letters, numerals, access codes, processed symbols or perforations that have meaning or can understood by people who are able to understand it. " Furthermore, Article 1 paragraph 4 states that "Electronic Documents are any electronic information that is made, forwarded, transmitted, received or stored in analog, digital, electromagnetic, optical or the like which can be seen, displayed and / or heard through a Computer or Electronic System, including through computers or electronic systems, including but not limited to writing, sound, images, maps, designs, photos or the like, letters, signs, numbers, access codes, symbols or perforations that have meaning or meaning or can be understood by people who are able understand it. " Basically the two definitions above can provide an overview of what is meant by electronic information and electronic documents. Likewise with several legal sanctions and compensation in article 45 of Regulations Number 19 of 2016 it is felt that legal sanctions and compensation claims can provide deterrent effects for perpetrators of criminal offenses violating decency, gambling, humiliation and defamation, extortion and / or threats, hoaxes, threats to the Race and Religion (SARA) and acts of violence. However, this Law does not specifically emphasize those who deliberately distribute and / or transmit and / or make
Electronic Information and / or Electronic Documents that have the confidentiality of documents and / or information regarding the practice of arbitration.

In national Arbitration practice, Indonesia has Regulations No. 30 of 1999 concerning Arbitration and Alternative Dispute Resolution. But in the provisions of Law Number 30 of 1999 it does not determine the use of AI (Artificial Intelligence). There are several articles in this Act that open the opportunity for the use of the AI (Artificial Intelligence) software program, such as the following articles:

Article 1 paragraph 3 "An arbitration agreement is an agreement in the form of an arbitration clause stated in a written agreement made by the parties before a dispute arises or a separate arbitration agreement is made after a dispute arises."

So it needs to be added

"Each arbitration agreement and related documents to use the AI (Artificial Intelligence) software program must have an agreement between the parties in a written agreement and signed by the parties.

Article 36 paragraph 1 "Examination of disputes in arbitration must be carried out in writing."

Article 36 paragraph 2 "Verbal examination can be carried out if agreed by the parties or deemed necessary by the arbitrator or arbitral tribunal."

$\underline{\text { Need to be added }}$

Examination of agreements and / or related documents in the settlement of arbitration disputes using an analysis of AI (Artificial Intelligence) is carried out if agreed by the parties to the agreement and signed by the parties.

Chapter X before the Transitional Provisions must also be added to the Legal Sanction stating some of the provisions below:

"Everyone intentionally and without rights distributes and / or transmits and / or makes accessible electronic information and electronic documents related to agreements 
and arbitration documents and dispute resolution sentenced to a maximum of 6 years in prison and / or a maximum fine of Rp. 1,000,000,000.00 (One billion Rupiah) "

"Everyone intentionally and without rights hack electronic information or electronic documents relating to the agreement and arbitration documents and dispute resolution are sentenced to a maximum of 6 years in prison and / or a maximum fine of Rp. 1,000,000,000.00 (One billion Rupiah). "

Some of the articles above are just sketches for legislation governing AI (Artificial Intelligence) in Arbitration practice. The making of this legal framework is a study of combining two different disciplines so that it uses two approaches namely the legal approach and the technological approach. For this reason, case studies of the weakness of AI (Artificial Intelligence) can be a legal approach in making these laws and regulations. Learning a number of case studies can find out how the work of Artificial Intelligence (AI) is not due to the convenience provided in the use of Artificial Intelligence (AI) but to follow the dominant paradigm of AI (Artificial Intelligence)

\section{CONCLUSION}

Some of the benefits of AI (Artificial Intelligence) are processing and evaluating tasks in international arbitration by analyzing the existence of international law in understanding national law, analyzing a number of legal documents on an online library database, using predictive coding programs that produce reviews and find documents in electronic format, using AI (Artificial Intelligence) to filter all relevant data to perceive documents, and evaluating with a high degree of accuracy the likelihood of success or failure of a party to the dispute. Still, the information storage of the AI (Artificial Intelligence) database can have a harmful impact and can endanger the business continuity of the parties, such as the Chatbot Tay case that smells of racism, the possibility of hacking, trade terrorism and so on. This dilemma is a challenge for law in Indonesia in the era of 4.0 industrial revolution because the laws and regulations in Indonesia have not explicitly regulated the use of AI (Artificial Intelligence) in international arbitration practices. It is suggested that research should be conducted in studying cases relating to the limitation of AI AI (Artificial Intelligence) so that it helps to facilitate the preparation of the legal framework in the use of AI (Artificial Intelligence) in international arbitration practice.

\section{REFERENCES}

[1] Article 1313 of the Civil Code of the Law "An agreement is an act by which one or more persons binds himself to one or more persons."
[2] Gil Press, Artificial Intelligence (AI) defined, https://www.forbes.com/sites/gilpress/2017/08/27/artifi cial-intelligence-ai-defined/\#78a5d3c7661a, August, 27 2017.

[3] What is artificial inteligence ?, https://www.bbc.com/news/av/technology34224406/what-is-artificial-intelligence

[4]Anggraeini and partners, Kecerdasan buatan (Artificial Intelligence) dan tantangan bagi Hukum Indonesia, $\quad$ https://aplawsolution.com/id/actio/kecerdasan-buatan-artificialintelligence-tantangann-ya-bagi-hukum-indonesia/, Jakarta.

[5] Kathleen Parsley and Edna Sussman, AI challenges and oppurtunities for International Arbitration, NYSBA New York Resolution Lawyer, Spring 2018, Volume II, No. $\quad 1, \quad$ https://sussmanadr.com/wpcontent/upload/2018/12/artificial-intelligence-inarbitration-nysba-spring-2018.

[6] Phillippe Billiet and Filip Nordlund, A New beginning - artificial intelligence and arbitration, http://www.kcab.or.kr/jsp/comm jsp/BasicDownload.j sp?FilePath=arbitration\%2Ff 0.1401400348113912615 21536471556\&orgName $=04 .+A+$ new + beginning $\% 26$ $\% 238211 \% 3 \mathrm{~B}+$ artificial+intelligence+and+arbitration+ \%28Philippe+Billiet\%2C+Filip+Nordlund\%29.pdf

[7] In 2014, a team from Chicago-Kent College of Law, This created an algorithm to predict the results of 7,700 decisions from the US Supreme Court, delivered between 1953 and 2013, reaching 70\% accuracy of results.

[8] Edwina L. Rissland, Artificial Intelligence and Law: Stepping Stones to a Model of Legal Reasoning, 99 Yale L.J. (1990), http://digitalcommons.law.yale.edu/ylj/vol99/iss8/4 